\title{
Impacto da Redução dos Encargos Trabalhistas sobre a Formalização das Empregadas Domésticas
}

\author{
Maria Isabel Accoroni Theodoro*, Luiz Guilherme Scorzafave ${ }^{\dagger}$
}

\author{
Conteúdo: 1. Introdução; 2. Algumas Considerações acerca do Trabalho Doméstico; \\ 3. Metodologia e Dados; 4. Análise Descritiva dos Dados; 5. Resultados; \\ 6. Conclusões.
}

Este artigo analisa o impacto da redução dos encargos trabalhistas (previstos na lei 11.324 de julho 2006) sobre a formalização das empregadas domésticas. Para a construção do grupo de controle foi adotada a metodologia de pareamento por escore de propensão e para estimar o efeito causal da lei sobre a formalização utilizou-se o estimador de diferenças-em-diferenças. Foram utilizados dados da Pesquisa Mensal de Emprego/IBGE dos anos de 2004 a 2007 e os resultados indicam um efeito inconclusivo da lei sobre a formalização, pois algumas estimativas mostraram efeitos positivos enquanto outras não foram significativas.

This article analyzes the impact of the decrease in work incumbencies (foreseen in the law number 11.324 of July 19th, 2006) over the legalization of house servant. To construct the control group it was adopted the Propensity Score Matching methodology and to estimate the causal effect of the law over formalization we implement a differences-in-differences estimator. It was used data from Pesquisa Mensal de Emprego for 2004 to 2007. The results concerning the law effect were inconclusive, as some estimates give a positive and significant effect while others do not show any effect.

Palavras-chave: Emprego Doméstico, Informalidade, Mulher

Códigos JEL: JEL Classification: J2, J38, J4

\footnotetext{
*Universidade de São Paulo. E-mail: isabel theodoro@yahoo.com.br
}

†Universidade de São Paulo. E-mail: scorza@usp.br 


\section{INTRODUÇÃO}

Desde o final dos anos 80 vem ocorrendo um aumento significativo da participação feminina no mercado de trabalho brasileiro. No entanto, apesar dessa maior inserção no mercado de trabalho, a maioria das ocupações nas quais as mulheres estão engajadas apresenta baixa remuneração e alto grau de informalidade. O exemplo mais importante de ocupação dessa natureza é o emprego doméstico, ocupação com maior número de postos de trabalho entre as mulheres. Segundo dados da Pesquisa Nacional por Amostra de Domicílios (PNAD), cerca de $17 \%$ do total de mulheres ocupadas no mercado de trabalho eram, em 2005, empregadas domésticas e dessas, somente $25 \%$ possuíam registro em carteira.

Outra peculiaridade do emprego doméstico é que ele dispõe de uma legislação específica e só passou a ser regulamentado em 1972. Nessa legislação foram estabelecidos alguns direitos a esses trabalhadores, como salário mínimo fixado em lei, férias de 20 dias úteis a cada doze meses de trabalhos prestados, aposentadoria e acesso aos serviços do INSS. Além disso, a partir da Constituição de 1988, tornou-se opcional para essa categoria o recolhimneto do FGTS e o pagamento do seguro-desemprego. Por sua vez, em 19 de julho de 2006, foi editada a lei $\mathrm{n}^{0}$ 11.324, que alterou a legislação do Imposto de Renda das Pessoas Físicas e introduziu a possibilidade de se deduzir do Imposto de Renda a contribuição paga à Previdência Social pelo empregador doméstico incidente sobre o valor da remuneração do empregado. O objetivo dessa lei é reduzir o elevado grau de informalidade vivenciado nesta ocupação estimulando o registro em carteira do emprego doméstico.

Até o presente momento, não há nenhum trabalho procurando avaliar se a lei conseguiu efetivamente alcançar seu objetivo. Assim, dado que a ocupação doméstica é a mais importante ocupação feminina e considerando que o governo está possibilitando a redução da carga tributária de uma parcela melhor posicionada na distribuição de renda (os patrões), embora com o legítimo objetivo de aumentar a formalização do emprego doméstico, cabe indagar se essa redução de encargos trabalhistas sobre o emprego doméstico vem efetivamente surtindo o efeito esperado. Desse modo, o presente trabalho analisa o impacto da redução desses encargos sobre a formalização das empregadas domésticas. Para tanto, utilizou-se a técnica de pareamento com escore de propensão e o estimador de diferenças-em-diferenças para garantir que tanto características observáveis como não observáveis pudessem ser devidamente controladas a fim de se garantir uma inferência não enviesada acerca da existência (ou não) de um efeito da lei sobre a formalização das empregadas domésticas.

O artigo está organizado em 5 seções além dessa Introdução. A seção seguinte apresenta algumas considerações acerca do trabalho doméstico e da legislação correspondente a essa ocupação. Na Seção 3 é apresentada a metodologia econométrica utilizada para avaliar empiricamente o efeito da legislação sobre a formalização das empregadas domésticas. Em seguida são apresentados os resultados e, por fim, a Seção 6 aborda as conclusões do trabalho.

\section{ALGUMAS CONSIDERAÇÕES ACERCA DO TRABALHO DOMÉSTICO}

Desde o final dos anos 80 o mercado de trabalho brasileiro vem passando por várias transformações importantes. Dentre elas, destacam-se a maior importância do setor de serviços no total de empregos em detrimento ao setor industrial, o aumento da informalidade e o contínuo aumento da participação feminina no mercado de trabalho (Arbache, 2001, DIEESE, 2006, Ulyssea, 2006).

Muitos trabalhos vêm buscando evidenciar o papel das instituições sobre a informalidade. Em geral há evidências de que rigidez contratual e os elevados custos trabalhistas são os principais motivos para a alta informalidade no Brasil (Ulyssea, 2006, Barros, 1993, Amadeo e Camargo, 1996). Cabe aqui ressaltar que esse resultado é encontrado para o conjunto dos trabalhadores, não apenas os empregados domésticos. Além disso, segundo Perry et alii (2007), também para as ocupações em geral, algumas 
características estão mais associadas ao emprego informal no Brasil. A informalidade é maior em empresas de pequeno porte e para trabalhadores com baixo nível educacional. Com relação ao emprego doméstico, as mulheres casadas e com filhos são as que apresentam maior taxa de informalidade.

No que diz respeito à maior participação feminina, alguns estudos já vem discutindo suas causas. Por exemplo, Scorzafave e Menezes-Filho (2001) citam como determinantes as condições da própria mulher (idade e escolaridade) e fatores relacionados à estrutura (background) familiar da qual ela faz parte (número de adultos, renda dos outros membros do domicílio, número de filhos em idades diferentes e a posição da mulher na família). Já Bruschini (2000) cita como principais determinantes para o caso brasileiro o aumento na escolaridade e a redução na taxa de fecundidade.

Entretanto, mesmo com o crescimento da entrada da mulher no mercado de trabalho, o emprego doméstico continua a ser uma ocupação preponderante entre as mulheres. Em 2005, existiam 6,6 milhões de empregados domésticos, ou seja, 7,6\% do total de pessoas ocupadas. Destas, 93\% (6,2 milhões) eram do sexo feminino, o que equivalia a $17 \%$ das mulheres ocupadas no mercado de trabalho, segundo os dados do IBGE (2005).

Entende-se por empregado doméstico aquele que presta serviços de natureza contínua e de finalidade não lucrativa à pessoa ou à família no âmbito residencial destas. ${ }^{1} \mathrm{O}$ trabalho doméstico é uma atividade econômica tradicionalmente feminina, provavelmente por motivos culturais, dado que os afazeres domésticos são tidos na sociedade brasileira como de responsabilidade da mulher, independente de sua posição social.

Segundo Melo (2000), desde a década de 90 as diversas tarefas do serviço doméstico se concentraram numa única pessoa. Dessa forma, o empregado doméstico passou a executar todas as tarefas de uma residência, como, por exemplo, cozinhar, lavar, passar e fazer faxina, atividades que anteriormente eram exercidas por trabalhadores específicos e hoje, na grande maioria das vezes, são realizadas por um único trabalhador. Esse fato pode ser explicado pela entrada da mulher no mercado de trabalho, que gerou a necessidade de um trabalhador que a substituísse e, assim, que concentrasse as várias funções que ela antes exercia como dona de casa.

De acordo com esse mesmo estudo, mais de $80 \%$ dos trabalhadores domésticos trabalhavam em apenas um domicílio. Melo ressalta que os trabalhadores dessa ocupação possuem um perfil característico: são mulheres jovens, casadas e de baixa escolaridade. A autora ressalta entretanto, que tanto a idade quanto a escolaridade média dos trabalhadores domésticos cresceram durante a década de 90.

Andrade (2004) diz que nos anos 90 o emprego doméstico deixou de ser visto como uma porta de entrada para o mercado de trabalho para mulheres de baixa escolaridade, migrantes do processo de urbanização ou como um trabalho de transição para trabalhos de maior prestígio e rendimentos na esfera produtiva. Dessa forma, essa ocupação deixou de ser caracterizada como uma ocupação de transição e passou a ser caracterizada como uma ocupação permanente com número de postos de trabalho crescente.

O emprego doméstico recebe uma remuneração mensal muito abaixo da remuneração média da economia (R\$ 270,00 e R $\$ 710,00$ em 2005 , respectivamente). No entanto, a referência do salário do trabalhador doméstico tende a ser o salário mínimo. Com os aumentos sucessivos do salário mínimo a partir de meados dos anos 90 , verificou-se um ligeiro crescimento da renda real média dos trabalhadores domésticos Melo (2000). Além dessa diferença de salários, a taxa de formalização dos trabalhadores também é muito menor que a do restante dos ocupados (25\% e 55\%, respectivamente) IBGE (2005).

O trabalho doméstico dispõe de uma legislação específica e só passou a ser regulamentado em 11 de dezembro de 1972 pela Lei $\mathrm{n}^{\circ}$ 5.859, na qual foram estabelecidos alguns direitos a esses trabalhadores, como salário mínimo fixado em lei, férias de 20 dias úteis a cada doze meses de trabalhos prestados, aposentadoria e acesso aos serviços do INSS. Além disso, a partir da Constituição de 1988, tornouse opcional para a categoria dos empregados domésticos o recolhimneto do FGTS e o pagamento do seguro-desemprego.

\footnotetext{
${ }^{1}$ Definição segundo a Lei n. 5.859 de 1972, que regulamenta a profissão.
} 
Em 19 de julho de 2006 foi editada a Lei $n^{0} 11.324$ alterando a legislação do Imposto de Renda das Pessoas Físicas e introduzindo a possibilidade de deduzir, do Imposto de Renda devido, a contribuição paga à Previdência Social pelo empregador doméstico incidente sobre o valor da remuneração do empregado. Essa dedução é limitada a apenas um empregado doméstico por declaração, ao valor recolhido no ano-calendário a que se referir a declaração e a dedução do Imposto de Renda não pode exceder o valor da contribuição patronal calculada sobre um salário mínimo mensal, sobre o décimo terceiro salário e sobre a remuneração adicional de férias, referidos também a um salário mínimo. ${ }^{2}$ Essa lei tem como objetivo aumentar o número de registros em carteira dos empregados domésticos, reduzindo os custos previdenciários incidentes para o empregador doméstico.

Além disso, a partir dessa lei, as férias passaram a ser de 30 dias corridos, em vez de vinte dias úteis e também é prevista estabilidade no emprego até o quinto mês após o parto. Cabe destacar que esse último aspecto da lei pode diminuir o impacto positivo da lei sobre o nível de formalização, contrabalançando o efeito da redução dos encargos trabalhistas. ${ }^{3}$

Por fim, cabe ressaltar que os trabalhadores domésticos ainda não fazem jus a adicional por hora extra, adicional noturno, salário-família, beneficio por acidente de trabalho, devendo esses ser acertados entre as partes na contratação.

\section{METODOLOGIA E DADOS}

\subsection{Procedimento metodológico}

A análise do efeito da redução dos encargos trabalhistas sobre a formalização dos empregados domésticos será feita por meio do estimador de diferenças-em-diferenças. Para utilizar esse estimador, a amostra será dividida em dois grupos: aqueles afetados pela nova legislação (grupo de tratamento) e aqueles não afetados (grupo de controle). A definição do grupo de controle será realizada com a implementação da técnica de pareamento ou matching.

Para se avaliar o efeito de uma política sobre os indivíduos tratados, o ideal seria observar esses mesmos indivíduos na ausência dessa política. Com isso, é necessário encontrar um contrafactual, ou seja, um grupo que represente qual teria sido o comportamento dos tratados na ausência do tratamento. Para a construção adequada desse contrafactual, a hipótese-chave que se adota é a chamada hipótese de independência condicional. Segundo ela, condicional nas características observáveis, a atribuição dos indivíduos ao grupo de tratamento ou ao de controle seria aleatória.

No nosso caso específico, essa hipótese implica que uma vez que controlamos por uma série de caracterísitcas observáveis, dois indivíduos possuiriam a mesma probabilidade de serem empregados domésticos. Ou seja, apesar de a escolha ocupacional do indivíduo estar longe de ser em evento aleatório, nossa hipótese é que as variáveis observáveis utilizadas são suficientes para, uma vez controladas, tornar a escolha ocupacional aleatória. Apesar de ser uma hipótese forte e considerando também o fato de que a Pesquisa Mensal de Emprego (PME), base de dados utilizada nessa pesquisa, não fornece uma riqueza muito grande de possíveis variáveis que afetem a escolha ocupacional, admitimos que condicional nessas variáveis (escolaridade, idade, município, cor, número de pessoas no domicílio, salário horário e posição na família), a escolha da ocupação doméstica seria aleatória.

Aqui, cabem algumas ressalvas que podem ocasionar a violação dessa hipótese. Pode-se argumentar que muitas dessas variáveis são endógenas com relação a escolha ocupacional. Além disso, podemos estar omitindo variáveis que são importantes na escolha ocupacional e que são diferentes entre os

\footnotetext{
${ }^{2} \mathrm{~A}$ alíquota de contribuição do empregador é de $12 \%$ e a do empregado doméstico é de $7 \%$. A lei se refere apenas a dedução dos $12 \%$. Se calculado sobre o valor de um salário mínimo em julho de 2006 , os $12 \%$ correspondiam a $R \$ 42,00$ por mês.

${ }^{3}$ Agradecemos a um parecerista anônimo por essa sugestão.
} 
indivíduos. Nesse sentido, nossos resultados devem ser analisados sob a perspectiva de que são válidos apenas sob a validade da hipótese de independência condicional.

Em suma, para a construção do grupo de controle, será utilizado o matching ou pareamento. Esse método consiste em selecionar algumas características dos indivíduos tratados e procurar indivíduos entre os demais da amostra que apresentem essas mesmas características. Portanto, para se obter uma estimativa não enviesada do tratamento, será preciso identificar um grupo de controle que seja o mais parecido possível com o grupo de tratamento em termos de características observadas. Para se evitar o problema de multidimensionalidade, utilizou-se aqui o método de pareamento por escore de propensão (propensity score matching). ${ }^{4}$ Por fim, vale ressaltar que essa técnica permite que estimemos o chamado efeito tratamento sobre os tratados (Average Treatment on Treated - ATT).

Como dito anteriormente, para analisar o impacto da mudança na legislação será utilizado o estimador de diferenças-em-diferenças. $O$ uso desse estimador permitirá eliminar o efeito de características individuais fixas não observadas dos indivíduos do processo de estimação. Embora não seja necessário o uso da informação do mesmo indivíduo antes e depois da lei para a implementação desse metódo, a estrutura de painel dos dados permite que seja feita uma hipótese menos restritiva para identificação do efeito do tratamento sobre a formalização.

Dessa forma, para implantar o método de diferenças-em-diferenças será estimado o seguinte modelo por Mínimos Quadrados Ordinários com dados dos períodos "antes" e "depois" da entrada em vigor da lei.

$$
Y_{i t}=\beta_{0}+\delta_{0} l e i_{i t}+\delta_{1} \text { mensalista }_{i t}+\beta_{1} \text { lei }_{i t} \text { mensalista }_{i t}+u_{i t}
$$

Em que o intercepto, $\beta_{0}$, é a formalização média dos indivíduos não afetados pela lei antes dela entrar em vigor. $O$ parâmetro $\delta_{0}$ captura as alterações na formalização de todos os indivíduos afetados pela lei, antes e depois de sua entrada em vigor. O coeficiente de mensalista, $\delta_{1}$, mede o efeito na formalização devido ao fato de uma pessoa ser trabalhadora doméstica mensalista. O parâmetro de interesse é $\beta_{1}$ que mede a variação na formalização das empregadas domésticas devida à nova lei.

\subsection{Dados e variáveis}

Para a estimação do escore de propensão, serão utilizadas apenas as informações do período pré-lei e a amostra é composta apenas por pessoas ocupadas. A variável dependente nesse caso será uma dummy indicando se a pessoa é empregada doméstica mensalista ou não.

Após o pareamento ter sido realizado com os indivíduos no período antes da lei, o método de diferenças-em-diferenças será aplicado estimando-se a equação (1) para os indíviduos pareados, utilizando agora informações dos mesmos em dois momentos do tempo: antes e depois da lei. Assim, nosso grupo de tratamento será constituído por mulheres mensalistas que estavam ocupadas tanto antes quanto depois da lei. Os dados usados nas estimações foram extraídos da Pesquisa Mensal de Emprego (PME/IBGE) para os anos de 2004, 2005, 2006 e 2007 para as regiões metropolitanas nas quais a PME coleta seus dados (São Paulo, Rio de Janeiro, Salvador, Recife, Porto Alegre e Belo Horizonte).

A PME é uma pesquisa que segue uma estrutura de painel rotativo na qual cada domicílio é entrevistado por quatro meses consecutivos e então é retirado da amostra por oito meses. Depois desse período, ele retorna para a amostra durante mais quatro meses. Dessa forma é possível obter oito observações do mesmo domicílio ao longo de dezesseis meses.

\footnotetext{
${ }^{4}$ Para maiores detalhes acerca do pareamento por escore de propensão e do problema de multidimensionalidade, ver, por exemplo, Rosenbaum e Rubin (1983) e Dehejia e Wahba (1998).
} 
Para que fosse possível efetuar a análise de interesse com os dados contidos na PME e aproveitar a estrutura de dados em painel da mesma, algumas observações do banco tiveram que ser excluídas. Assim, permaneceram na amostra somente indivíduos que responderam a pesquisa pela $1^{a}, 2^{a}, 3^{a}$ ou $4^{a}$ vez no mês de dezembro de 2005 e pela $5^{a}, 6^{a}, 7^{a}$ ou $8^{a}$ vez em dezembro de 2006 , ou seja, o indivíduo que respondeu a pesquisa pela $1^{a}$ vez em dezembro de 2005 e pela $5^{a}$ vez em dezembro de 2006 permaneceu no banco, assim como o indivíduo que respondeu pela $2^{a}$ vez em dezembro de 2005 e pela $6^{a}$ vez em dezembro de 2006 e assim, sucessivamente. Dessa forma, foi possível obter informações do mesmo indivíduo antes e depois da lei entrar em vigor (no dia 16 de julho de 2006). Para a realização das análises de robustez, também foram utilizadas informações dos meses de janeiro a junho de 2006 (antes da lei) e de janeiro a junho de 2007 (depois da lei), bem como referentes ao ano de 2004.

As variáveis contidas na PME e utilizadas neste trabalho foram: ocupação doméstica, número de empregos (no caso das domésticas), renda do trabalho e horas semanalmente trabalhadas (usadas para o cálculo do salário por hora), posse de registro em carteira, sexo, posição que ocupa na família (chefe, cônjuge ou outra), número de moradores do domicílio, município, idade, escolaridade e raça. ${ }^{5}$

Como na pesquisa não existe a pergunta se a empregada doméstica é mensalista ou diarista, considerou-se nesse trabalho como diarista a empregada doméstica com mais de um trabalho na semana e mensalista a empregada doméstica com apenas um trabalho semanal.

O fato de estarmos trabalhando o efeito da lei apenas sobre as mensalistas que já estavam nessa posição na ocupação antes da lei e que permaneceram como mensalistas após a lei poderia gerar algumas inconsistências na análise. Por exemplo, se a lei proporcionou uma migração de mulheres de outras ocupações para o emprego doméstico com carteira assinada, podemos estar enviesando nossos resultados. Com o intuito de averiguar se isso estava ocorrendo, utilizamos os dados da Pesquisa Nacional por Amostra de Domicílios (PNAD) dos anos de 2003 a 2007. Foi estimado um modelo Probit da probabilidade de uma mulher ser empregada doméstica, condicional em variáveis observadas (similares às que foram utilizadas a partir da PME), acrescentando-se dummies de ano a fim de averiguarmos se após a lei houve um aumento na probabilidade de uma mulher ocupada ser empregada doméstica mensalista. A ideia de se usar a PNAD decorre do fato de que sua amostra é muito maior que a da PME, mas a desvantagem é que ela não apresenta a estrutura de dados em painel.

\section{ANÁLISE DESCRITIVA DOS DADOS}

Em nosso trabalho, excluímos do grupo de tratamento algumas pessoas potencialmente afetadas pela lei. Assim, trabalhadoras que antes da lei não eram domésticas, mas que passaram a ser depois da lei não fazem parte do nosso grupo de tratamento (e nem do grupo de controle). Uma questão que pode ser levantada é se essas transições para o emprego doméstico poderiam provocar um viés na estimação do efeito da lei. Nesse sentido, a Figura 1 apresenta a evolução temporal da fração de empregadas domésticas mensalistas e diaristas, relativamente ao total de trabalhadoras para o período de janeiro de 2004 a dezembro de 2007.

Por meio da Figura 1 é possível observar que a porcentagem de mulheres que eram empregadas domésticas (tanto diaristas quanto mensalistas) não se alterou ao redor do período de implantação da lei, julho de 2006, e nem mesmo até junho de 2007. Isto sugere que não houve uma migração para o emprego doméstico em decorrência da lei. Mesmo se analisarmos a proporção de diaristas, também não houve uma diminuição desse grupo após a lei. Portanto, parece que a implementação da lei não foi antecipada pelas potenciais afetadas, no sentido de induzir uma mudança ocupacional.

Outra importante análise pode ser feita por meio da Tabela 1, a qual apresenta a taxa média de formalização semestral para o período de 2004 a 2007.

\footnotetext{
${ }^{5}$ Devido à limitação imposta pela PME, não foi possível utilizarmos um maior número de variáveis explicativas neste trabalho.
} 
Figura 1: Proporção de domésticas no total de trabalhadoras
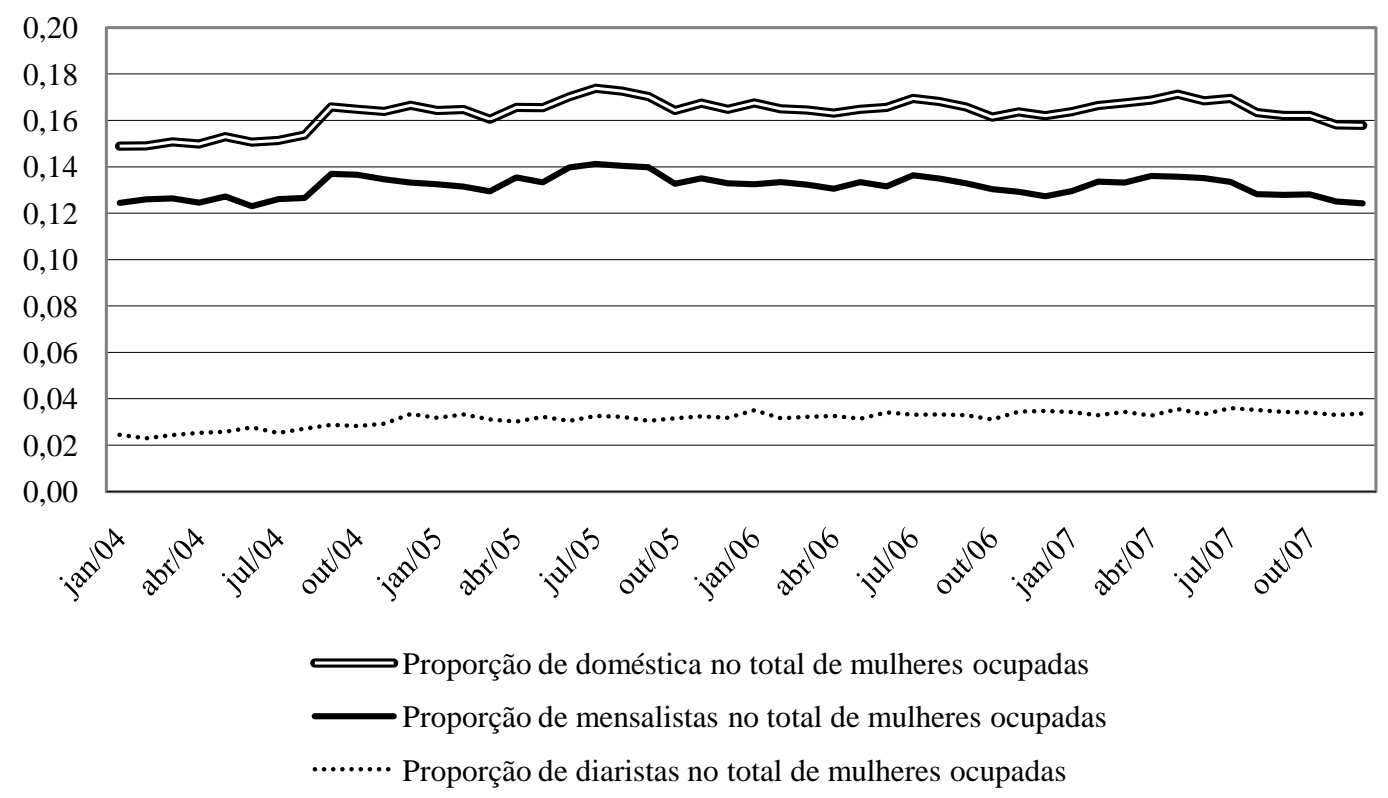

Tabela 1: Taxa média de formalização e taxa de variação semestrais - (\%)

\begin{tabular}{ccccccc}
\hline & $\begin{array}{c}\text { Trabalhadoras } \\
\text { em geral exceto } \\
\text { domésticas }\end{array}$ & $\begin{array}{c}\text { Taxa de } \\
\text { variação } \\
\text { semestral }\end{array}$ & $\begin{array}{c}\text { Trabalhadoras } \\
\text { domésticas } \\
\text { (diaristas+mensalistas) }\end{array}$ & $\begin{array}{c}\text { Taxa de } \\
\text { variação } \\
\text { semestral }\end{array}$ & $\begin{array}{c}\text { Trabalhadoras } \\
\text { domésticas } \\
\text { mensalistas }\end{array}$ & $\begin{array}{c}\text { Taxa de } \\
\text { variação } \\
\text { semestral }\end{array}$ \\
\hline $1^{\circ}$ semestre/2004 & 69,1 & - & 35,5 & - & 40,1 & - \\
$2^{\circ}$ semestre/2004 & 69,0 & $-0,1$ & 33,1 & $-6,6$ & 38,0 & $-5,4$ \\
$1^{\circ}$ semestre/2005 & 69,9 & 1,3 & 35,2 & 6,4 & 41,1 & 8,2 \\
$2^{\circ}$ semestre/2005 & 71,2 & 1,8 & 34,6 & $-1,7$ & 39,9 & $-2,8$ \\
$1^{\circ}$ semestre/2006 & 71,3 & 0,1 & 33,8 & $-2,2$ & 39,6 & $-0,8$ \\
$2^{\circ}$ semestre/2006 & 70,9 & $-0,5$ & 34,4 & 1,8 & 40,9 & 3,2 \\
$1^{\circ}$ semestre/2007 & 72,1 & 1,7 & 34,6 & 0,5 & 41,0 & 0,4 \\
$2^{\circ}$ semestre/2007 & 73,2 & 1,5 & 35,5 & 2,5 & 42,3 & 3,0 \\
Média do período & 70,8 & 0,8 & 34,6 & 0,1 & 40,4 & 0,8 \\
\hline
\end{tabular}

Fonte: PME 2004, 2005, 2006 e 2007. 
Pode ser observado na Tabela 1 que a taxa média de formalização das trabalhadoras domésticas no período de 2004 a 2007 foi de 34,6\%, um valor muito abaixo da taxa média do grupo de trabalhadoras em geral exceto as domésticas que foi $70,8 \%$. Além disso, a taxa de formalização média das empregadas domésticas mensalistas, foco principal do nosso trabalho, é de 40,4\%, também bem abaixo da taxa das trabalhadoras em geral exceto domésticas.

Figura 2: Taxa de formalização mensal de janeiro de 2004 a dezembro de 2007

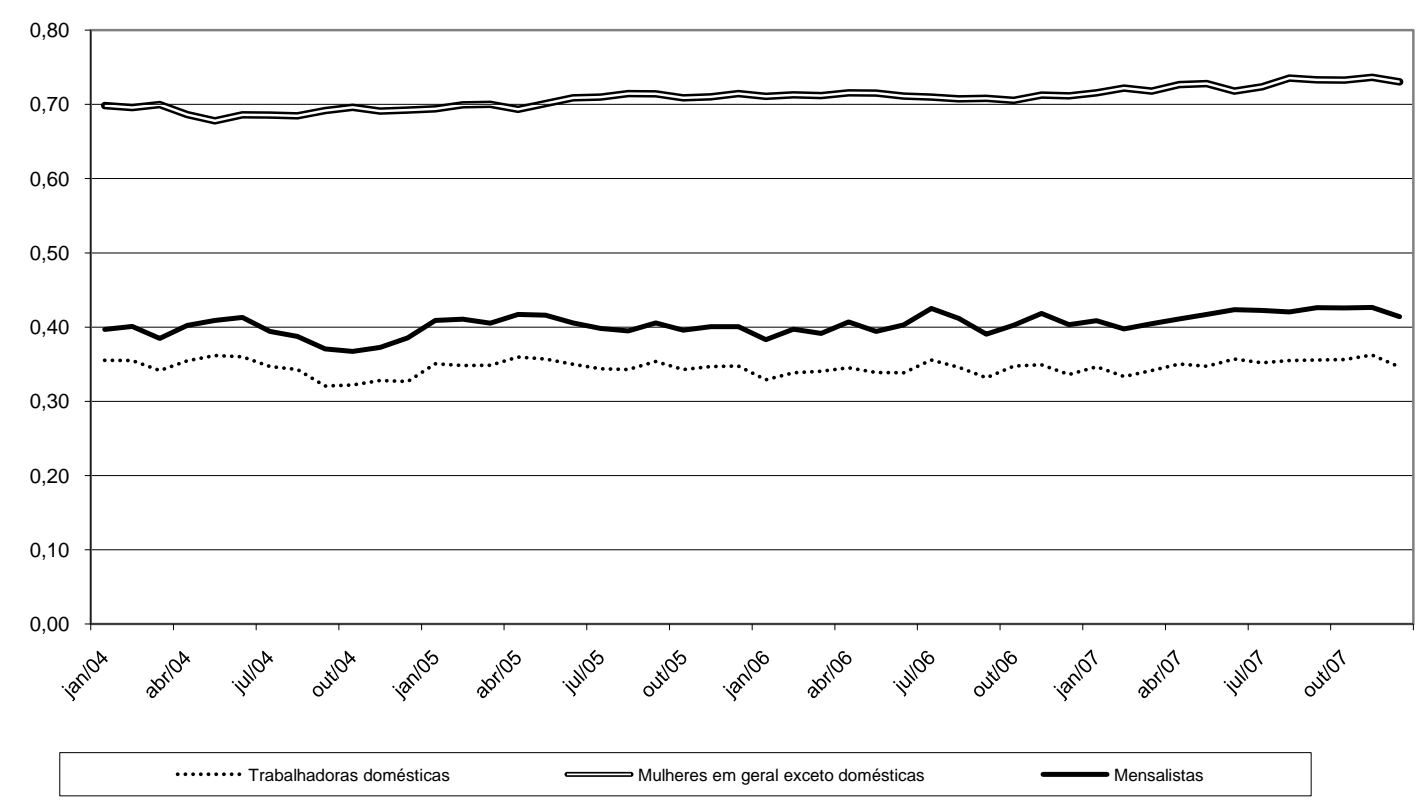

Na Figura 2 é possível verificar que a taxa média de formalização das trabalhadoras domésticas, diaristas mais mensalistas e somente mensalistas, oscilam muito mais no período analisado do que a do grupo das mulheres em geral exceto domésticas. Além disso, aparentemente não há uma mudança de padrão da variável taxa de formalização para as trabalhadoras domésticas mensalistas após a entrada em vigor da lei, em julho de 2006.

Além da análise feita acima, na qual se observa a variável de interesse ao longo do tempo, também é interessante observar na Tabela 2 essas mesmas variáveis juntamente às outras variáveis que serão utilizadas na estimação do escore de propensão, somente nos meses de dezembro de 2005 (antes da mudança na legislação) e dezembro de 2006 (depois da mudança). ${ }^{6}$

Por meio da Tabela 2, é possível verificar que a variação da taxa de formalização das trabalhadoras em geral exceto domésticas entre dezembro de 2005 e dezembro de 2006 foi de 1,87\%, enquanto para as trabalhadoras domésticas mensalistas foi de $-6,86 \%$. Esse resultado é o oposto do esperado, dado que a lei entrou em vigor em julho de 2006. No entanto, observa-se também no mesmo período de análise, que a taxa de variação do salário médio por hora foi maior para o grupo de domésticas mensalistas, $15,70 \%$, enquanto para o outro grupo foi de $8,51 \%$.

Além disso, pode-se observar na Tabela 2 que o número de moradores no domicílio e a idade média permaneceram praticamente constantes nos dois grupos em dezembro de 2005 e dezembro de 2006 . 0 grupo das trabalhadoras em geral é constituído em sua maioria por brancas, aproximadamente 58\%,

\footnotetext{
${ }^{6}$ Esses dois meses foram utilizados para coletar as informações que serão necessárias para calcular o estimador de diferençasem-diferenças em sua especificação inicial.
} 
Tabela 2: Variáveis do Probit no grupo das trabalhadoras em geral exceto doméstico e no grupo das trabalhadoras domésticas mensalistas em dezembro de 2005 e dezembro de 2006

\begin{tabular}{|c|c|c|c|c|c|c|}
\hline & \multicolumn{3}{|c|}{$\begin{array}{l}\text { Trabalhadoras em geral } \\
\text { exceto domésticas }\end{array}$} & \multicolumn{3}{|c|}{$\begin{array}{c}\text { Trabalhadoras domésticas } \\
\text { mensalistas }\end{array}$} \\
\hline & dez-05 & dez-06 & Variação(\%) & dez-05 & dez-06 & Variação(\%) \\
\hline Taxa de formalização (\%) & 72,14 & 73,48 & 1,87 & 41,13 & 38,31 & $-6,86$ \\
\hline Salário por hora & 5,85 & 6,35 & 8,51 & 2,42 & 2,80 & 15,70 \\
\hline Número de moradores no domicílio & 3,72 & 3,71 & $-0,23$ & 3,80 & 3,73 & $-1,84$ \\
\hline Idade & 34,89 & 34,86 & $-0,08$ & 40,32 & 41,50 & 2,93 \\
\hline Brancos & 58,52 & 58,09 & $-0,73$ & 39,17 & 34,66 & $-11,51$ \\
\hline Cônjuge & 18,39 & 18,31 & $-0,44$ & 44,76 & 46,43 & 3,73 \\
\hline Chefe & 47,72 & 45,78 & $-4,07$ & 38,40 & 39,49 & 2,84 \\
\hline Sem instrução e menos de 1 ano de estudo & 1,76 & 1,40 & $-20,45$ & 8,99 & 8,53 & $-5,12$ \\
\hline De 1 a 3 anos de estudo & 3,98 & 3,81 & $-4,27$ & 13,46 & 12,81 & $-4,83$ \\
\hline De 4 a 7 anos de estudo & 19,54 & 18,41 & $-5,78$ & 44,20 & 44,01 & $-0,43$ \\
\hline De 8 a 10 anos de estudo & 19,44 & 18,05 & $-7,15$ & 20,94 & 21,59 & 3,10 \\
\hline 11 ou mais anos de estudo & 55,09 & 58,23 & 5,70 & 11,72 & 12,69 & 8,28 \\
\hline Anos de estudo não determinados & 0,19 & 0,11 & $-42,11$ & 0,69 & 0,37 & $-46,38$ \\
\hline Recife & 4,82 & 5,01 & 3,94 & 4,47 & 4,17 & $-6,71$ \\
\hline Salvador & 5,61 & 5,72 & 1,96 & 8,54 & 9,39 & 9,95 \\
\hline Belo Horizonte & 10,57 & 10,77 & 1,89 & 12,38 & 11,28 & $-8,89$ \\
\hline Rio de Janeiro & 25,58 & 24,16 & $-5,55$ & 30,16 & 28,72 & $-4,77$ \\
\hline São Paulo & 44,90 & 46,21 & 2,92 & 37,09 & 40,44 & 9,03 \\
\hline Porto Alegre & 8,52 & 8,14 & $-4,46$ & 7,35 & 6,00 & $-18,37$ \\
\hline
\end{tabular}

Fonte: PME dezembro de 2005 e dezembro de 2006.

tendo praticamente nenhuma variação de dezembro de 2005 para dezembro de 2006 , e por $18,39 \%$ de cônjuges e $47,72 \%$ de chefes em dezembro de 2005 . Diferentemente, o grupo das trabalhadoras domésticas mensalistas não é formado em sua maioria por brancas (o percentual de brancas é menor que $40 \%$, variando cerca de $-11 \%$ entre dezembro de 2005 e dezembro de 2006 ) e praticamente se divide entre cônjuge e chefe (aproximadamente $45 \%$ e $38 \%$, respectivamente, em ambos os períodos).

Outra informação importante obtida por meio da Tabela 2 é que o número de anos de escolaridade das trabalhadoras em geral exceto domésticas é muito superior ao das domésticas mensalistas. Considerando dezembro de 2006, verifica-se que enquanto 58,23\% das trabalhadoras em geral tinham 11 anos ou mais de estudo, apenas $12,69 \%$ das mensalistas se encontravam nessa mesma categoria.

Por fim, observando as taxas de variação dos diferentes níveis de escolaridade, um fato que chama a atenção é a proporção de trabalhadoras domésticas sem instrução e menos de um ano de escolaridade que diminuiu apenas $5,12 \%$ entre as domésticas mensalistas, enquanto no grupo das trabalhadoras em geral exceto domésticas diminuiu $20,45 \%$ no mesmo período.

\section{RESULTADOS}

Inicialmente estimou-se o modelo Probit, para que fosse encontrada a probabilidade de um indivíduo ocupado ser uma mulher trabalhadora doméstica mensalista. Os resultados encontram-se na Tabela 3.

A amostra utilizada no Probit constitui-se de pessoas ocupadas (trabalhadores formais e informais) em um período anterior à vigência da lei (dezembro de 2005); entretanto, para possibilitar a implementação do método de diferenças em diferenças, considerou-se apenas os trabalhadores que também apareciam na PME como ocupadas em dezembro de 2006. Dessa forma, na estimação do Probit apenas as informações dessas pessoas no período pré-lei foram utilizadas. Observa-se que as variáveis explica- 
Tabela 3: Resultados do modelo Probit

\begin{tabular}{|c|c|}
\hline & Trabalhadoras domésticas mensalistas \\
\hline \multirow[t]{2}{*}{ Idade } & $0,020^{* * *}$ \\
\hline & $(0,003)$ \\
\hline \multirow[t]{2}{*}{ Branco } & $-0,139^{* *}$ \\
\hline & $(0,0680)$ \\
\hline \multirow[t]{2}{*}{ Total de moradores no domicílio } & $-0,050^{* *}$ \\
\hline & $(0,021)$ \\
\hline \multirow[t]{2}{*}{ Salário por hora } & $-0,326^{* * *}$ \\
\hline & $(0,036)$ \\
\hline \multirow[t]{2}{*}{ Sem instrução e menos de 1 ano de estudo } & $0,893^{* * *}$ \\
\hline & $(0,149)$ \\
\hline \multirow[t]{2}{*}{ De 1 a 3 anos de estudo } & $0,721^{* * *}$ \\
\hline & $(0,126)$ \\
\hline \multirow[t]{2}{*}{ De 4 a 7 anos de estudo } & $0,662^{* * *}$ \\
\hline & $(0,088)$ \\
\hline \multirow[t]{2}{*}{ De 8 a 10 anos de estudo } & $0,333^{* * *}$ \\
\hline & $(0,093)$ \\
\hline \multirow[t]{2}{*}{ Recife } & $-0,374^{* * *}$ \\
\hline & $(0,116)$ \\
\hline \multirow[t]{2}{*}{ Salvador } & $-0,041$ \\
\hline & $(0,106)$ \\
\hline \multirow[t]{2}{*}{ Belo Horizonte } & $-0,048$ \\
\hline & $(0,088)$ \\
\hline \multirow[t]{2}{*}{ Rio de Janeiro } & $-0,002$ \\
\hline & $(0,087)$ \\
\hline \multirow[t]{2}{*}{ Porto Alegre } & $-0,115$ \\
\hline & $(0,100)$ \\
\hline \multirow[t]{2}{*}{ Chefe } & $-0,039$ \\
\hline & $(0,097)$ \\
\hline \multirow[t]{2}{*}{ Cônjuge } & $0,497^{* * *}$ \\
\hline & $(0,093)$ \\
\hline \multirow[t]{2}{*}{ Constante } & $-1,539^{* * *}$ \\
\hline & $(0,184)$ \\
\hline número de observações & 7536 \\
\hline Pseudo R2 & 0,229 \\
\hline${ }^{*} p \leq 0.10, * * p \leq 0.05,{ }^{* * *} p \leq 0.01$ & \\
\hline
\end{tabular}


tivas apresentaram os sinais esperados. Dessa forma, pode-se concluir que ser branco, morar na região metropolitana de Recife (quando comparada à São Paulo), ter mais anos de estudo e um salário mais alto são fatores que diminuem a probabilidade de uma pessoa ser trabalhadora doméstica. Por sua vez, ter idade mais avançada e ser cônjuge aumentam a probabilidade de ser trabalhadora doméstica.

Dado isso, para ser possível realizar o pareamento sobre o vetor de covariadas $X$, a partir da estimativa do Probit, obteve-se o escore de propensão $p(X)$, que consiste na probabilidade condicional de um indivíduo receber o tratamento dado um vetor de características observáveis $X$. O pareamento foi implementado via pareamento do vizinho mais próximo (nearest neighbor matching) e sem reposição. $O$ pareamento foi calibrado à 0,0002 (caliper matching), sendo esta a maior distância permitida entre as probabilidades estimadas dos indivíduos pareados.

Observando a Figura 3, da distribuição de probabilidade $p(X)$ dos dois grupos, é possível avaliar a qualidade do pareamento. Quanto mais parecidas forem as distribuições, melhor terá sido o pareamento. Verifica-se uma semelhança razoavelmente alta entre eles, principalmente para escores acima de 0,1 , evidenciando uma boa qualidade do matching realizado.

Figura 3: Propensity Score (0 controle -1 tratamento)

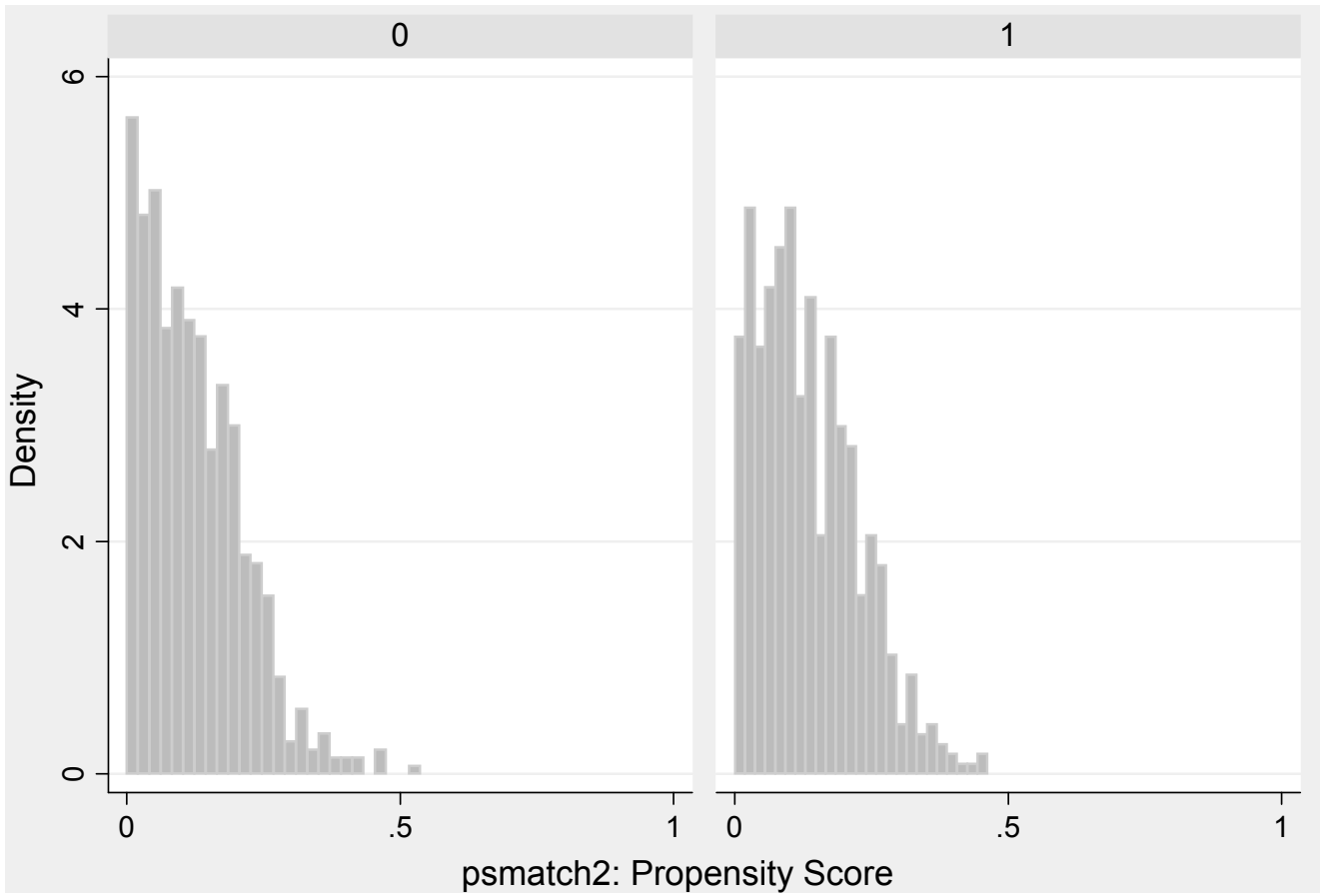

Além da inspeção visual da figura 3, foram implementadas duas outras medidas da qualidade do matching. Uma delas é o pseudo R2 o qual indica quão bem as variáveis explicativas explicam a probabilidade de uma pessoa ser uma trabalhadora doméstica. Antes do matching o pseudo R2 era 0,24 e após o matching passou para 0,013, o que era esperado, dado que após o matching espera-se que não exista diferença nas variáveis observáveis entre os indivíduos pareados.

A outra medida de qualidade do matching é o teste de diferença de médias das covariadas usadas no Probit, o qual pode ser visto na Tabela 4. Praticamente todas as variáveis explicativas utilizadas tinham médias diferentes entre os grupos de tratamento e controle antes do pareamento; após o pareamento nenhuma variável possuia média diferente nos dois grupos, evidenciando que os grupos são parecidos em observáveis. 
Tabela 4: Resultados do $t$-teste antes e após a realização do matching

\begin{tabular}{|c|c|c|c|c|c|c|c|}
\hline \multicolumn{8}{|c|}{ Médias } \\
\hline Variáveis & Amostra & Tratados & Controles & $\%$ de viés & $\begin{array}{c}\text { \% de redução } \\
\text { \% (viés) }\end{array}$ & t-test & $\begin{array}{l}\text { p-valor } \\
\text { do t-test }\end{array}$ \\
\hline \multirow[t]{2}{*}{ Idade } & Unmatched & 41,259 & 35,165 & 53,6 & & 11,06 & 0,000 \\
\hline & Matched & 39,261 & 38,336 & 8,1 & 84,8 & 1,08 & 0,282 \\
\hline \multirow[t]{2}{*}{ Branco } & Unmatched & 0,383 & 0,561 & $-36,3$ & & $-7,48$ & 0,000 \\
\hline & Matched & 0,438 & 0,408 & 6,1 & 83,2 & 0,78 & 0,434 \\
\hline Total de moradores & Unmatched & 36,261 & 36,962 & $-4,5$ & & $-0,98$ & 0,329 \\
\hline no domicílio & Matched & 37,508 & 36,937 & 3,7 & 18,6 & 0,45 & 0,653 \\
\hline \multirow[t]{2}{*}{ Salário por hora } & Unmatched & 23,376 & 56,163 & $-58,4$ & & $-8,94$ & 0,000 \\
\hline & Matched & 25,066 & 24,599 & 0,8 & 98,6 & 0,53 & 0,594 \\
\hline Sem instrução menos e & Unmatched & 0,100 & 0,016 & 36,6 & & 12,33 & 0,000 \\
\hline de 1 ano de estudo & Matched & 0,051 & 0,048 & 1,3 & 96,4 & 0,18 & 0,859 \\
\hline \multirow[t]{2}{*}{ De 1 a 3 anos de estudo } & Unmatched & 0,128 & 0,042 & 31,1 & & 8,44 & 0,000 \\
\hline & Matched & 0,111 & 0,117 & $-2,2$ & 93,0 & $-0,24$ & 0,808 \\
\hline \multirow[t]{2}{*}{ De 4 a 7 anos de estudo } & Unmatched & 0,461 & 0,205 & 56,4 & & 12,97 & 0,000 \\
\hline & Matched & 0,426 & 0,480 & $-11,9$ & 78,9 & $-1,40$ & 0,162 \\
\hline \multirow[t]{2}{*}{ De 8 a 10 anos de estudo } & Unmatched & 0,191 & 0,194 & $-0,8$ & & $-0,16$ & 0,874 \\
\hline & Matched & 0,246 & 0,207 & 9,9 & $-1195,1$ & 1,20 & 0,230 \\
\hline \multirow[t]{2}{*}{ Recife } & Unmatched & 0,074 & 0,089 & $-5,6$ & & $-1,12$ & 0,264 \\
\hline & Matched & 0,081 & 0,078 & 1,1 & 80,3 & 0,14 & 0,886 \\
\hline \multirow[t]{2}{*}{ Salvador } & Unmatched & 0,135 & 0,098 & 11,6 & & 2,57 & 0,010 \\
\hline & Matched & 0,132 & 0,096 & 11,3 & 2,9 & 1,46 & 0,144 \\
\hline \multirow[t]{2}{*}{ Belo Horizonte } & Unmatched & 0,209 & 0,197 & 3,0 & & 0,63 & 0,532 \\
\hline & Matched & 0,216 & 0,267 & $-12,7$ & $-326,3$ & $-1,54$ & 0,124 \\
\hline \multirow[t]{2}{*}{ Rio de Janeiro } & Unmatched & 0,252 & 0,200 & 12,6 & & 2,72 & 0,007 \\
\hline & Matched & 0,204 & 0,201 & 0,7 & 94,3 & 0,10 & 0,923 \\
\hline \multirow[t]{2}{*}{ Porto Alegre } & Unmatched & 0,122 & 0,159 & $-10,8$ & & $-2,14$ & 0,033 \\
\hline & Matched & 0,150 & 0,156 & $-1,7$ & 83,9 & $-0,21$ & 70,830 \\
\hline \multirow[t]{2}{*}{ Chefe } & Unmatched & 0,422 & 0,500 & $-15,7$ & & $-3,25$ & 0,001 \\
\hline & Matched & 0,474 & 0,526 & $-10,3$ & 34,7 & $-1,32$ & 0,188 \\
\hline \multirow[t]{2}{*}{ Cônjuge } & Unmatched & 0,433 & 0,188 & 54,9 & & 12,81 & 0,000 \\
\hline & Matched & 0,345 & 0,294 & 11,4 & 79,2 & 1,41 & 0,158 \\
\hline
\end{tabular}

Fonte: PME dezembro de 2005 e dezembro de 2006.

Como dito anteriormente, a análise do efeito da redução dos encargos trabalhistas sobre a formalização das empregadas domésticas mensalistas foi feita por meio do estimador de diferenças-emdiferenças. Na amostra pareada, estimou-se a regressão (1), por meio da qual foi possível obter uma estimativa do parâmetro de interesse, $\beta_{1}$. Como período anterior a lei, adotou-se dezembro de 2005 e como período posterior à lei, dezembro de 2006.

Os resultados, que podem ser observados na Tabela 5, evidenciam que a variável de interesse (lei*mensalista) é positiva quanto a formalização, porém, não significativa, o que indicaria que a mudança na legislação não surtiu efeito sobre a taxa de formalização das trabalhadoras domésticas no período analisado.

\subsection{Testes de Robustez}

A análise dos resultados da Tabela 5 deve ser feita com cautela, pois pode ser que o resultado se deva ao fato de termos trabalhado com os meses de dezembro de 2005 e dezembro de 2006 especificamente. 
Tabela 5: Resultados do modelo Probit (dezembro de 2005 e dezembro de 2006)

\begin{tabular}{lc}
\hline & Trabalhadoras domésticas mensalistas \\
\hline lei*mensalista & 0,072 \\
& $(0,063)$ \\
mensalista & $-0,134^{* * *}$ \\
& $(0,044)$ \\
lei & $-0,051$ \\
& $(0,043)$ \\
constante & $0,632^{* * *}$ \\
& $(0,031)$ \\
R2 & 0,009 \\
Número de observações & 1332 \\
${ }^{*} p \leq 0.10,{ }^{* *} p \leq 0.05,{ }^{* * *} p \leq 0.01$ & \\
\hline Fonte: PME dezembro de 2005 e dezembro de 2006. &
\end{tabular}

Com o objetivo de testar a robustez dos resultados e captar um eventual efeito inercial da lei sobre a formalização, já que os empregadores poderiam demorar certo período de tempo para terem conhecimento acerca da mesma, foi estimado o mesmo modelo (1) alterando-se o período de análise para os meses de janeiro de 2006 contra janeiro de 2007, fevereiro de 2006 contra fevereiro de 2007, março 2006 contra março de 2007, abril de 2006 contra abril de 2007, maio de 2006 contra maio de 2007 e junho de 2006 contra junho de 2007. Em cada um dos casos, o pareamento foi feito com as informações do mês pré-lei correspondente.

Como pode ser visto na Tabela 6, o parâmetro de interesse continua não significativo nos meses de janeiro, março e abril, porém, nos outros meses analisados o parâmetro passou a ser significativo. Essa alternância de resultados sugere que tenhamos cautela acerca do efeito da alteração na legislação sobre a taxa de formalização dessas trabalhadoras.

Tabela 6: Resultados da estimação de diferenças em diferenças para os meses entre janeiro e junho

\begin{tabular}{lcccccc}
\hline \multicolumn{7}{c}{ Trabalhadoras domésticas mensalistas } \\
\hline \multirow{4}{*}{ lei*mensalista } & jan/06 & fev/06 & mar/06 & abr/06 & mai/06 & jun/06 \\
& jan/07 & fev/07 & mar/07 & abr/07 & mai/07 & jun/07 \\
& 0,099 & $0,140^{* *}$ & 0,074 & 0,033 & $0,141^{* *}$ & $0,119^{* *}$ \\
mensalista & $(0,065)$ & $(0,062)$ & $(0,057)$ & $(0,059)$ & $(0,060)$ & $(0,058)$ \\
& $-0,165^{* * *}$ & $-0,248^{* * *}$ & $-0,201^{* * *}$ & $-0,148^{* * *}$ & $-0,173^{* * *}$ & $-0,223^{* * *}$ \\
lei & $(0,046)$ & $(0,043)$ & $(0,040)$ & $(0,042)$ & $(0,042)$ & $(0,041)$ \\
& $-0,014$ & $-0,106^{* *}$ & $-0,048$ & $-0,019$ & $-0,077^{*}$ & $-0,063$ \\
constante & $(0,045)$ & $(0,043)$ & $(0,039)$ & $(0,041)$ & $(0,041)$ & $(0,039)$ \\
& $0,615^{* * *}$ & $0,660^{* * *}$ & $0,651^{* * *}$ & $0,631^{* * *}$ & $0,635^{* * *}$ & $0,659^{* * *}$ \\
R2 & $(0,032)$ & $(0,030)$ & $(0,028)$ & $(0,029)$ & $(0,029)$ & $(0,028)$ \\
Número de obs. & 0,015 & 0,035 & 0,027 & 0,016 & 0,014 & 0,028 \\
${ }^{*} p \leq 0.10,{ }^{* *} p \leq 0.05, * * * p \leq 0.01$ & & & & 1.4484 \\
\hline
\end{tabular}

Fonte: PME 2006 e 2007.

Um segundo ponto a ser considerado é que alguns estados apresentavam na ocasião da lei salários mínimos regionais maiores que o nacional, inclusive com pisos específicos para empregadas domésticas. Assim, a presença desses estados na amostra poderia estar viesando para baixo o efeito da lei sobre a 
formalização. ${ }^{7}$ Nesse sentido, excluímos da amostra as regiões metropolitanas do Rio de Janeiro e de Porto Alegre, dado que a legislação desses estados previa salário mínimo mais alto que o nacional para os trabalhadores domésticos. Dessa forma, seguem na Tabela 7 os resultados das estimações de diiferenças-em-diferenças excluindo as duas regiões metropolitanas da amostra para os mesmos pares de meses analisados anteriormente.

Como pode ser visto na Tabela 7 a exclusão dessas regiões metropolitanas fez com que o coeficiente referente a março06-março07 passasse a ser significante. Assim, apenas as estimações com os dados de dezembro e abril se mostraram não significativas.

Tabela 7: Resultados da regressão para os meses entre janeiro e junho excluindo as regiões metropolitanas do Rio de Janeiro e Porto Alegre

\begin{tabular}{|c|c|c|c|c|c|c|c|}
\hline \multicolumn{8}{|c|}{ Trabalhadoras domésticas mensalistas } \\
\hline & $\operatorname{dez} / 05$ & jan/06 & fev/06 & $\operatorname{mar} / 06$ & $\mathrm{abr} / 06$ & mai/06 & jun/06 \\
\hline & $\operatorname{dez} / 06$ & $\mathrm{jan} / 07$ & fev/07 & $\mathrm{mar} / 07$ & $\mathrm{abr} / 07$ & $\mathrm{mai} / 07$ & jun/07 \\
\hline \multirow[t]{2}{*}{ lei*mensalista } & 0,071 & $0,150^{* * *}$ & $0,167^{* * *}$ & $0,099^{*}$ & 0,079 & $0,106^{*}$ & $0,123^{* *}$ \\
\hline & $(0,061)$ & $(0,057)$ & $(0,062)$ & $(0,057)$ & $(0,057)$ & $(0,059)$ & $(0,057)$ \\
\hline \multirow[t]{2}{*}{ mensalista } & $-0,142^{* * *}$ & $-0,217^{* * *}$ & $-0,205^{* * *}$ & $-0,207^{* * *}$ & $-0,215^{* * *}$ & $-0,122^{* * *}$ & $-0,220^{* * *}$ \\
\hline & $(0,043)$ & $(0,040)$ & $(0,044)$ & $(0,040)$ & $(0,040)$ & $(0,042)$ & $(0,040)$ \\
\hline \multirow[t]{2}{*}{ lei } & $-0,048$ & $-0,063$ & $-0,107^{* *}$ & $-0,071^{*}$ & $-0,033$ & $-0,026$ & $-0,072^{*}$ \\
\hline & $(0,042)$ & $(0,040)$ & $(0,043)$ & $(0,039)$ & $(0,038)$ & $(0,041)$ & $(0,039)$ \\
\hline \multirow[t]{2}{*}{ constante } & $0,632^{* * *}$ & $0,679^{* * *}$ & $0,615^{* * *}$ & $0,637^{* * *}$ & $0,695^{* * *}$ & $0,601^{* * *}$ & $0,676^{* * *}$ \\
\hline & $(0,030)$ & $(0,029)$ & $(0,031)$ & $(0,028)$ & $(0,027)$ & $(0,030)$ & $(0,028)$ \\
\hline $\mathrm{R} 2$ & 0,011 & 0,024 & 0,02 & 0,026 & 0,032 & 0,007 & 0,027 \\
\hline Número de obs. & 1.404 & 1.192 & 1.320 & 1.552 & 1.492 & 1.444 & 1.568 \\
\hline \multicolumn{8}{|c|}{${ }^{*} p \leq 0.10, * * p \leq 0.05, * * * p \leq 0.01$} \\
\hline
\end{tabular}

Outra análise interessante a ser feita consiste em estimar um Probit com as mesmas variáveis utilizadas anteriormente, controlando os efeitos de mudanças agregadas que tenham afetado ambos os grupos por meio da introdução de variáveis dummies para cada ano. Essa análise também permite captar se houve alteração no tempo na probabilidade de uma mulher ocupada escolher a ocuapção doméstica mensalista. Para essa estimação utilizou-se dados das PNADs de 2003 a 2007 para pessoas ocupadas nas mesmas seis regiões metropolitanas em que a PME é realizada e os resultados podem ser vistos na Tabela 8.

Observa-se na Tabela 8 que os resultados são parecidos com a estimação utilizando dados da PME. As diferenças consistem em que nesse caso, ser chefe tem impacto positivo sobre a probabilidade de ser mensalista e ser cônjuge e ter mais idade impactam negativamente. Além disso, nenhuma dummy de ano se revelou significante, o que indica não ter havido nesse intervalo de tempo nenhuma alteração significativa na probailidade de a mulher ser empregada doméstica. Assim, corroboramos o resultado de que a lei não foi antecipada pelas potenciais beneficiárias.

Por fim, com o objetivo de medir o chamado efeito placebo, isto é, tentar captar o efeito de algum fator que eventualmente ocorresse todo ano e que estivesse sendo responsável pelo resultado encontrado, estimou-se a mesma regressão de diferenças-em-diferenças para períodos anteriores à alteração da legislação (para os meses de dezembro de 2004 contra dezembro de 2005, janeiro de 2005 contra janeiro de 2006, fevereiro de 2005 contra fevereiro de 2006, março 2005 contra março de 2006, abril de 2005 contra abril de 2006, maio de 2005 contra maio de 2006 e junho de 2005 contra junho de 2006).

Como se pode verificar na Tabela 9, o parâmetro de interesse foi significativo em apenas 2 casos. No entanto, as evidências apresentadas nessa seção não permitem que tiremos uma conclusão definitiva

\footnotetext{
${ }^{7}$ Agradecemos a um parecerista anônimo por essa observação
} 
Tabela 8: Resultados do modelo Probit utilizando dados da PNAD de 2003 a 2007

\begin{tabular}{|c|c|}
\hline & Trabalhadoras domésticas mensalistas \\
\hline \multirow[t]{2}{*}{ Idade } & $-0,006^{* * *}$ \\
\hline & $(0,001)$ \\
\hline \multirow[t]{2}{*}{ Branco } & $-0,057^{* * *}$ \\
\hline & $(0,021)$ \\
\hline \multirow[t]{2}{*}{ Total de moradores no domicílio } & $-0,046^{* * *}$ \\
\hline & $(0,007)$ \\
\hline \multirow[t]{2}{*}{ Salário por hora } & $-0,000^{* *}$ \\
\hline & 0,000 \\
\hline \multirow[t]{2}{*}{ Sem instrução e menos de 1 ano de estudo } & $1,202^{* * *}$ \\
\hline & $(0,099)$ \\
\hline \multirow[t]{2}{*}{ De 1 a 3 anos de estudo } & $1,096^{* * *}$ \\
\hline & $(0,099)$ \\
\hline \multirow[t]{2}{*}{ De 4 a 7 anos de estudo } & $0,957^{* * *}$ \\
\hline & $(0,098)$ \\
\hline \multirow[t]{2}{*}{ De 8 a 10 anos de estudo } & $0,686^{* * *}$ \\
\hline & $(0,100)$ \\
\hline \multirow[t]{2}{*}{ De 11 a 14 anos de estudo } & $0,217^{* *}$ \\
\hline & $(0,104)$ \\
\hline \multirow[t]{2}{*}{ Recife } & $-0,152^{* * *}$ \\
\hline & $(0,037)$ \\
\hline \multirow[t]{2}{*}{ Salvador } & $-0,059^{*}$ \\
\hline & $(0,030)$ \\
\hline \multirow[t]{2}{*}{ Belo Horizonte } & 0,008 \\
\hline & $(0,028)$ \\
\hline \multirow[t]{2}{*}{ Rio de Janeiro } & $0,251^{* * *}$ \\
\hline & $(0,028)$ \\
\hline \multirow[t]{2}{*}{ Porto Alegre } & $-0,02$ \\
\hline & $(0,032)$ \\
\hline \multirow[t]{2}{*}{ Ano 2003} & 0,005 \\
\hline & $(0,031)$ \\
\hline \multirow[t]{2}{*}{ Ano 2004} & $-0,028$ \\
\hline & $(0,031)$ \\
\hline \multirow[t]{2}{*}{ Ano 2005} & $-0,025$ \\
\hline & $(0,031)$ \\
\hline \multirow[t]{2}{*}{ Ano 2007} & $-0,019$ \\
\hline & $(0,031)$ \\
\hline \multirow[t]{2}{*}{ Chefe } & $0,251^{* * *}$ \\
\hline & $(0,028)$ \\
\hline \multirow[t]{2}{*}{ Cônjuge } & $-0,462^{* * *}$ \\
\hline & $(0,050)$ \\
\hline \multirow[t]{2}{*}{ Constante } & $-3,129^{* * *}$ \\
\hline & $(0,111)$ \\
\hline Número de observações & 468.845 \\
\hline Pseudo R2 & 0,1004 \\
\hline$* p \leq 0.10,{ }^{* *} p \leq 0.05,{ }^{* * *} p \leq 0.01$ & \\
\hline
\end{tabular}

Fonte: PNAD 2003, 2004, 2005, 2006 e 2007. 
Tabela 9: Resultados da regressão para os meses entre dezembro de 2004 e junho e junho de 2006 Placebo

\begin{tabular}{lccccccc}
\hline \multicolumn{7}{c}{ Trabalhadoras domésticas mensalistas } \\
\hline \multirow{4}{*}{ lei*mensalista } & dez/04 & jan/05 & fev/05 & mar/05 & abr/05 & mai/05 & jun/05 \\
& dez/05 & jan/06 & fev/06 & mar/06 & abr/06 & mai/06 & jun/06 \\
\cline { 2 - 8 } mensalista & 0,096 & $-0,005$ & 0,031 & $0,121^{*}$ & 0,064 & 0,091 & $0,106^{*}$ \\
& $(0,059)$ & $(0,053)$ & $(0,060)$ & $(0,063)$ & $(0,062)$ & $(0,060)$ & $(0,059)$ \\
lei & $-0,220^{* * *}$ & $-0,103^{* *}$ & $-0,101^{* *}$ & $-0,151^{* * *}$ & $-0,07$ & $-0,108^{* *}$ & $-0,207^{* * *}$ \\
& $(0,041)$ & $(0,041)$ & $(0,043)$ & $(0,044)$ & $(0,044)$ & $(0,042)$ & $(0,041)$ \\
Constante & $-0,047$ & 0,013 & $-0,005$ & $-0,074^{*}$ & $-0,024$ & $-0,059$ & $-0,056$ \\
& $(0,041)$ & $(0,035)$ & $(0,042)$ & $(0,042)$ & $(0,043)$ & $(0,041)$ & $(0,040)$ \\
R2 & $0,636^{* * *}$ & $0,584^{* * *}$ & $0,578^{* * *}$ & $0,677^{* * *}$ & $0,603^{* * *}$ & $0,630^{* * *}$ & $0,659^{* * *}$ \\
Número de obs. & $(0,030)$ & $(0,028)$ & $(0,030)$ & $(0,030)$ & $(0,031)$ & $(0,029)$ & $(0,029)$ \\
$*$ & 1.500 & 2.000 & 1.476 & 1.328 & 1.368 & 1.464 & 1.456 \\
\hline
\end{tabular}

Fonte: PME 2004, 2005 e 2006.

acerca do efeito da lei sobre a formalização, dada a instabilidade dos resultados encontrados de acordo com o período analisado.

\section{CONCLUSÕES}

A ocupação doméstica é um dos mais importantes campos de inserção feminina no mercado de trabalho. Suas características (grande número de postos trabalho entre as mulheres, baixa formalização e baixo salário) a tornam candidata a estudos mais aprofundados acerca do seu funcionamento. Nesse sentido, o presente trabalho se propôs a analisar o impacto da legislação referente à redução dos encargos trabalhistas sobre a taxa de formalização das trabalhadoras domésticas. Para isso, foram utilizados dados da PME (e de forma secundária da PNAD) e buscou-se avaliar os efeitos da redução dos encargos trabalhistas por meio do estimador de diferenças em diferenças.

Levando em consideração as evidências aqui mostradas, não se pode classificar o esforço do governo em reduzir os encargos trabalhistas incidentes sobre esta ocupação como instrumento eficaz de aumento da formalização devido aos resultados inconclusivos encontrados; em alguns casos houve aumento na formalização e em outros, não.

Além disso, essa política pode ter um efeito retardado no tempo, ou seja, pode ser que os empregadores domésticos não estejam informados a respeito desse benefício fiscal ou que precisem de mais tempo para se adaptar. Pode ser que apenas na ocasião de declarar o imposto de renda o empregador acabe descobrindo a possibilidade do abatimento da contribuição patronal para o INSS do empregado doméstico. Se a lei entrou em vigor em 2006 , provavelmente muitos patrões só tiveram conhecimento da mesma no primeiro semestre de 2007, à época da entrega da declaração do Imposto de Renda e o ano seguinte, 2008, não é analisado neste trabalho. De qualquer modo, mesmo após considerarmos o comportamento em junho de 2007, não houve alteração nos resultados que levassem a alguma conclusão mais clara a respeito da eficácia da lei. 


\section{BIBLIOGRAFIA}

Amadeo, E. \& Camargo, J. M. (1996). Instituições e o mercado de trabalho no Brasil. In Camargo, J. (org). Flexibilidade no Mercado de Trabalho no Brasil. Fundação Getúlio Vargas, Rio de Janeiro.

Andrade, A. S. C. (2004). Trabalho feminino e desvantagem social: Diferenciais de raça e cor no emprego doméstico. XIV Encontro Nacional de Estudos Populacional, ABEP.

Arbache, J. S. (2001). Liberalização comercial e mercado de trabalho no Brasil. In Lisboa, M. B. \& Menezes-Filho, N., editors, Microeconomia e Sociedade no Brasil, pages 251-284. Contra Capa Livraria, Rio de Janeiro.

Barros, R. (1993). The informal labor market in Brazil. mimeo.

Bruschini, C. (2000). Trabalho e gênero - mudanças, permanências e desafios. In Rocha, M. I. B., editor, Gênero e Trabalho no Brasil: Novas Conquistas ou Persistência da Discriminação, pages 13-58. Editora 34, Campinas.

Dehejia, R. H. \& Wahba, S. (1998). Propensity score matching methods for non-experimental causal studies. NBER working paper, 6829.

DIEESE (2006). Incentivo à formalização do emprego doméstico. Nota técnica-n.25.

IBGE (2005). Pesquisa nacional por amostras de domicílios. Indicadores.

Melo, H. P. (2000). Trabalhadoras domésticas: 0 eterno lugar feminino. uma análise dos grupos ocupacionais. Estratégias para combater o trabalho infantil no serviço doméstico, Organização Internacional do Trabalho-OIT e Instituto de Pesquisa Econômica Aplicada-IPEA.

Perry, G. E., Maloney, W. F., Arias, O. S., Fajnzylber, P., Mason, A. D., \& Saavedra-Chanduvi, J. (2007). Informality: Exit and exclusion. Washington, World Bank.

Rosenbaum, P. R. \& Rubin, D. B. (1983). The central role of the propensity score in observational studies for causal effects. Biometrika, 70(1):41-55.

Scorzafave, L. \& Menezes-Filho, N. (2001). Participação feminina no mercado de trabalho brasileiro: Evolução e determinantes. Pesquisa e Planejamento Econômico, 31(3):441-478.

Ulyssea, G. (2006). Informalidade no mercado de trabalho brasileiro: uma resenha da literatura. Revista de Economia Política, 26(4):596-618. 